\title{
An Analysis of the Structural Particularity with Habitability Factors Using Value Engineering Process towards New-Hanok Villages in Korea
}

\author{
[ Pham Ngoc Quynh Giao, Jong-Il Park and Seung-Hoon Han ]
}

\begin{abstract}
This study followed previous researches in order to identify the elements to assess the feasibility of the life and activities of modern life in the traditional residential area of South Korea called New-Hanok Village, checked the evaluation methods for the components of it in the aspect of urban planning . Concentricity on the analysis of the next steps to evaluate the factors of living in New-Hanok, in addition, it has also been given from the results of the survey and analyzed in order to see an important element of New-Hanok from expert surveys. Through assessment and analysis, contracture and designers, tendering would have a more detailed view of the important elements of New-Hanok, could ascend the essential excogitation, the details of constituent, with the construction methods to reduce costs and condense fabrication time.
\end{abstract}

Keywords-New-Hanok Village, Structural Particularity, Habitability, Evaluation Index, Informal Appraisal

\section{Introduction}

In previous articles, we've discussed the process generating the elements assessed value of Hanok village by going through the decisive and timely replacement of the procedure, the database, the designers, builders to reduce construction time and costs for the project. Contemporaneous, we have also studied the role of VE in the design process can help to design and construct the building phase promote swiftly and more efficiently.

In this paper, we will prosecute to classify and study of the composition of Hanok. Through factors such as inherited traditions and local customs, climate, location, size, landscape and environment are classified to make the assessment for new types of Hanok village in Korea.

Quynh Giao Ngoc Pham, Jong-Il Park and Seung-Hoon Han*

School of Architecture, Chonnam National University, Korea

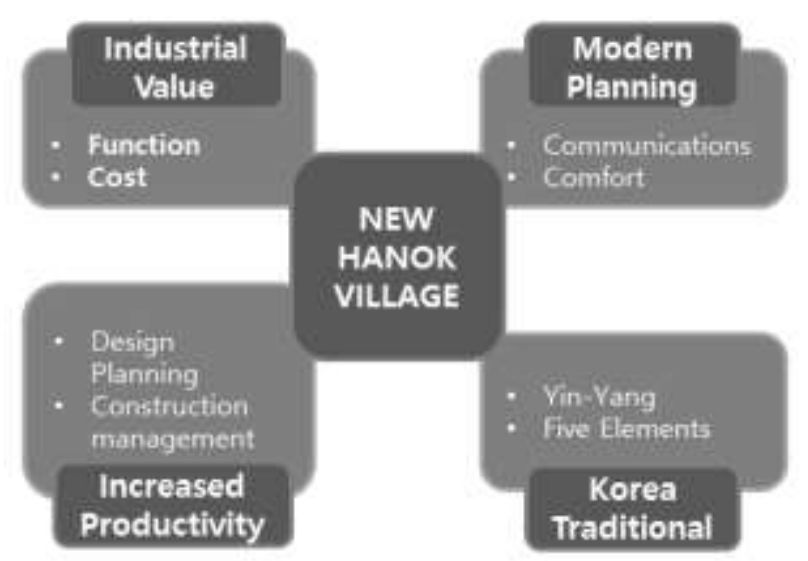

Figure 1. Expected Evaluation Factors for Hanok Village

\section{Yield in the direction of Architecture of Industrial}

\section{A. What's Productivity?}

Productivity can be defined basically as a measure expressing the average production efficiency, can be expressed as the ratio of output to be used in the manufacturing process, meaning that yields on an input unit. [2]

Results input and we are determined in total productivity measure as the economic value of the system. When we do calculations all input and result output, including performance measurement, it is defined as total production.

Production methods which typically use one or more input or countless distinguise factors, notwithstanding are not going to use all these factors, it is known as partial productivity.

Unanticipated conditions on a construction project in the long run result in a significant loss of productivity. The conditions that may affect productivity-adverse weather, scheduled overtime, and material shortages... Furthermore, when such losses are observed, their extent varies from project to project, from activity to activity, and from crew to crew. Other factors and processes must therefore be involved. [3]

On the other hand, in combination, we have assessed the key elements for effective productivity of labor, investment 
Proc. of The Third Intl. Conf. On Advances in Applied Science and Environmental Technology - ASET 2015 Copyright ( $)$ Institute of Research Engineers and Doctors, USA .All rights reserved.

ISBN: 978-1-63248-084-2 doi: 10.15224/ 978-1-63248-084-2-50

and related technologies ... It should be noted, the industry can be classification of each part of productivity, value added, aggregate and total yield by the method of measurement for the AEC (Architecture, Engineering and Construction). The reason is in Korea, the business Hanok and the traditional home of ancient culture here, which is a hybrid type of strenuous industrial activity, were skilled with many other difficult elements, who production worker from the genres typically manipulated. [1]

\section{B. Elements and Adjudicate to Productivity Growth}

In chart 3 below, an element of productivity in the construction sector can be described five stages: The natural factors, social factors, elements of design planning and construction constituents administrative. Through these elements are recommended, we learned want to improve productivity in the construction sector can be applied to eliminate or reduce these problems are expected to hinder the improvement of the inputs and the production systems.[4]

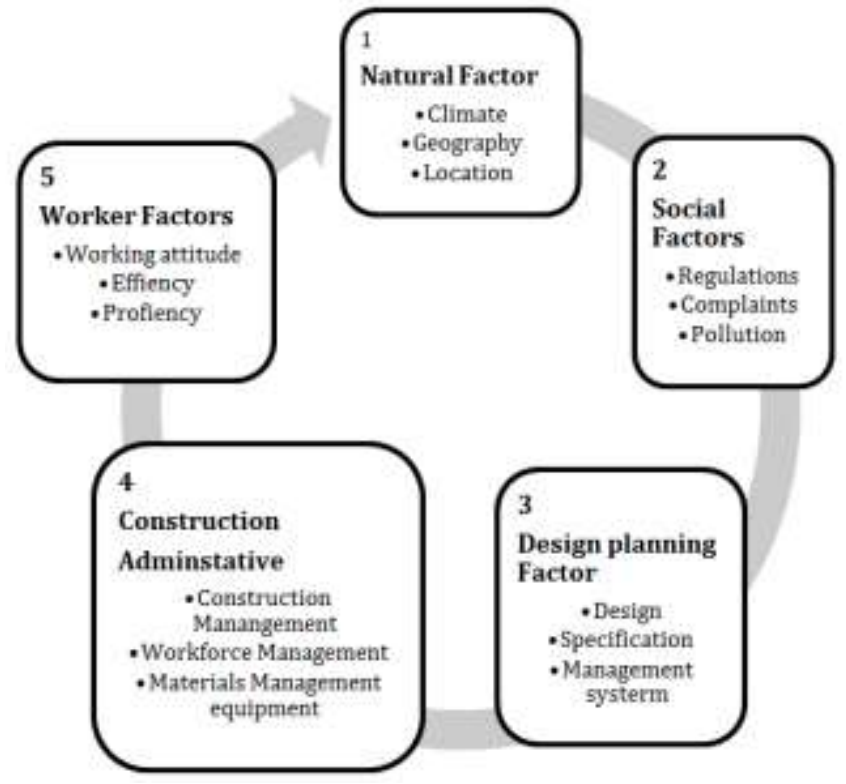

Figure 2. Classification of Productivity Factors (Source: Korean Institute of Construction Industry)

\section{Application of Value Engineering Process}

\section{A. Effect of the Value Engineering}

Design value assessment is one of VE processes for architectural projects. In this step, a digital spatial model for rating qualities is normally made by $3 \mathrm{D}$ tool and it helps expert find further necessary information and details for the design process. 3D models also enable expert to examine designs thoroughly and manage a field of construction and maintenance as the following businesses.
For example, Department of Transportation in the United States of America has applied a variety of design VE projects, and they includes 282 SOC (Social Overhead Capital) projects in 1996 with the subsidies by U.S. government and 1083 policy suggestions, and it counts $4 \mathrm{VE}$ suggestions per project in average. Before the design $\mathrm{VE}$, the presumed cost was 6.2 billion and 12 million dollars, but after the design VE, it was significantly decreased to 5.6 billion and 368 million dollars. Finally, the cost could be saved for $10 \%$.

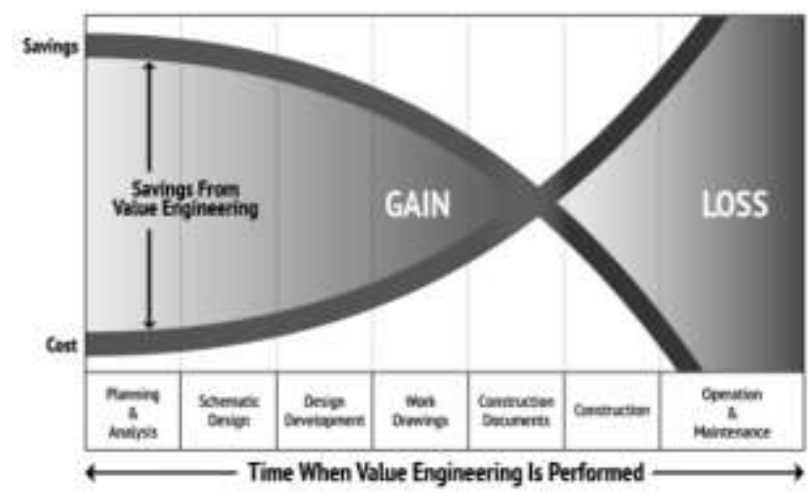

Figure 3. Effect of Value Engineering [3]

\section{B. Intelligent VE Process Improvements}

Therefore, $\mathrm{VE}$ in the design process may offer high possibility to manufracture better alternative designs and can accept change of other things, because the final design and the whole contents of the project are not yet decided. It is assumed that $\mathrm{VE}$ in the design stage is more effectively and has possibility to disparate cost than the construction phase.

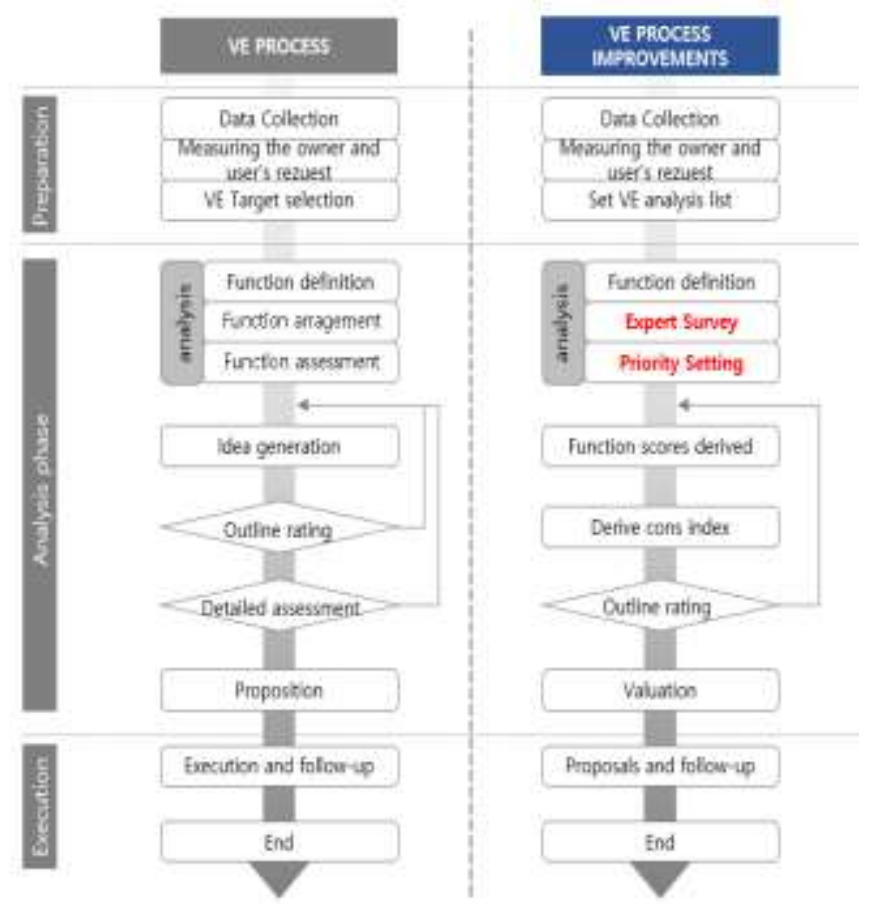

Figure 4. Intelligent VE Process Improvements [5] 
Proc. of The Third Intl. Conf. On Advances in Applied Science and Environmental Technology - ASET 2015

Copyright $(\odot$ Institute of Research Engineers and Doctors, USA .All rights reserved.

ISBN: 978-1-63248-084-2 doi: 10.15224/ 978-1-63248-084-2-50

\section{Iv. Innovation of the Assessment System for the New-Hanok Village}

\section{A. Features of New-Hanok}

Traditional Hanok, considered as an alternative for a convenient space to occupy and activities, is seen as a modern residence valuable. Whereas the traditional Hanok has a long average chronicle, as there are many different perceptions of the value of its existence, it is very difficult to modernize the space of the New-Hanok such as by changing the material, whimsical interior design. The establishment of the NewHanok definition through examination of research on it will help to establish the following:

The main structure of the New-Hanok including columns, beams and roof systems, were called Giwa, made of wood and were followed traditional style. The interior can be modernized and equipped with modern home and close the door at the front can thus be innovative. A new type Hanok village as the case include a more refined 10 housing units and are eternally surrounded by a harmonious landscape with modern living conditions.[4]

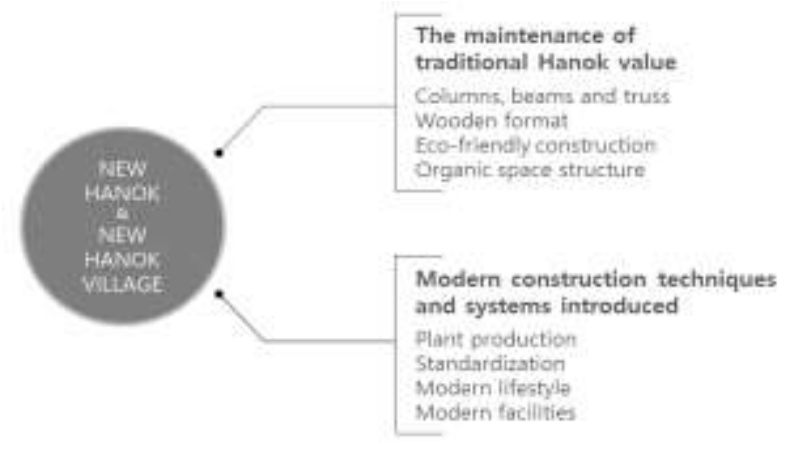

Figure 5. Definition of New-Hanok

\section{B. Habitability Factors for New-Hanok Village}

In a previous article, to synthesize a full list of the important factors of New-Hanok village, we have analyzed the principles or traditional Hanok Village is a pilot and NewHanok to determine a new evaluation index as follows:

- Analysis Framework for modern residential area

- Analyze the planning element for Korean traditional village

- Analysis of the planning element for the city of NewHanok

- Component classification and reorganization [6]

In this article we will continue to focus on research evaluation items are follows:

- Expert Survey
Selecting the key element has been the experts surveyed to draw the structural particularity of Hanok-Village

- Paired Comparison

Ponderosity fountainhead by a comparison distinguish between two objects typical to find another location and the same basic structure

\section{Valuation of New-Hanok Village}

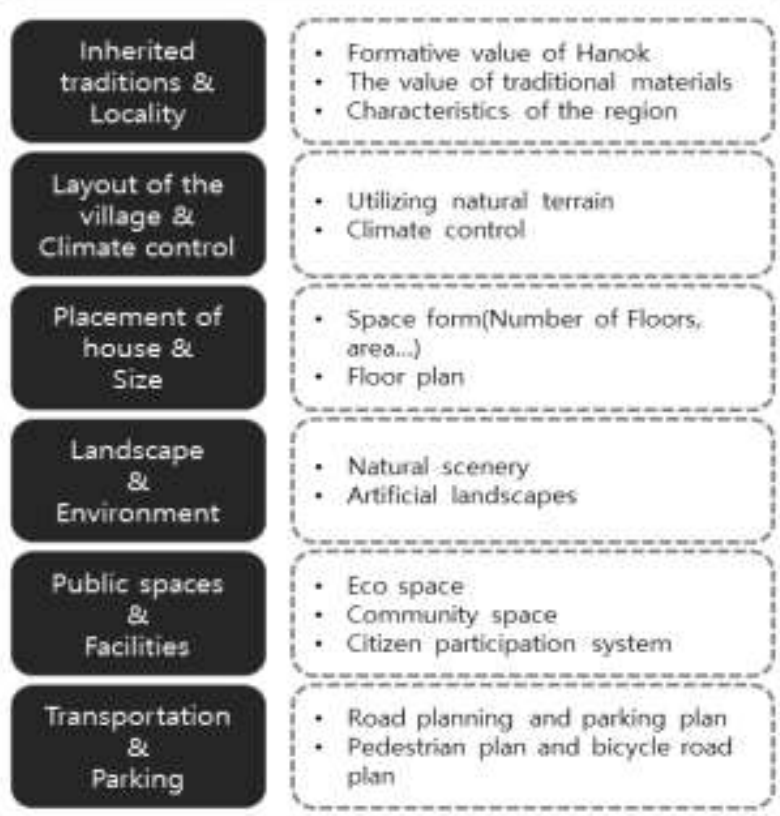

Figure 6. Evaluation Elements for Habitability of New-Hanok

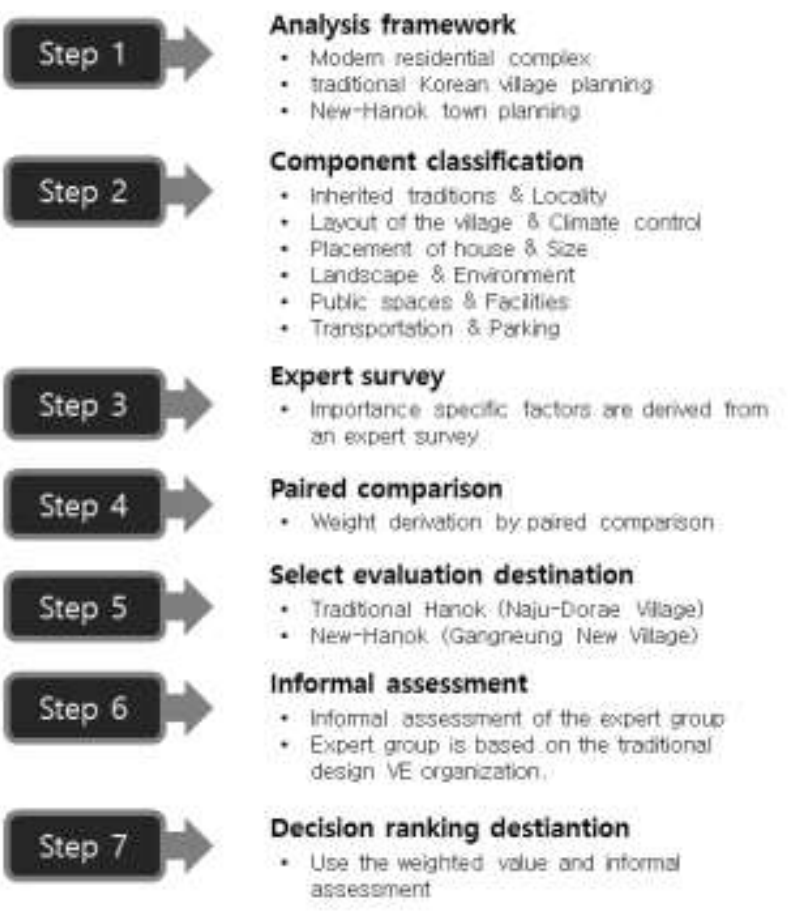

Figure 7. Creation Process of the Evaluation System for Residences in the New-Hanok Village 
Proc. of The Third Intl. Conf. On Advances in Applied Science and Environmental Technology - ASET 2015 Copyright ( Institute of Research Engineers and Doctors, USA .All rights reserved.

ISBN: 978-1-63248-084-2 doi: 10.15224/ 978-1-63248-084-2-50

- Selected Destination Evaluation

Selection of suitable locations to assess the elements constituting Traditional Hanok (namely Naju-Dorae Village) and New-Hanok (namely Gangneung New Village)

- Informal Assessment

Conduct informal authentication of experts and the expert group was the basis for the organization of traditional design VE Implement the informal appraisal by experts

\section{Performance of VE Process for New- Hanok Village}

1) Expert surveys and Paired confrontation

The graph below shows the degree of Importance from elements of New-Hanok and the gap between elements in Landscape \& Environment that achieves the highest points. This is the most important factor and 5.9 is the lowest point for the index of Transportation \& Parking. The other principal factor gets 9 points for the Placement of House \& Size, followed by the layout of the village \& Climate control with a score of 8.5. The result shows that the advantage of the surroundings and landscape of New-Hanok prioritizes the placement and size of the residence besides climate control factors are positioned in sequence.

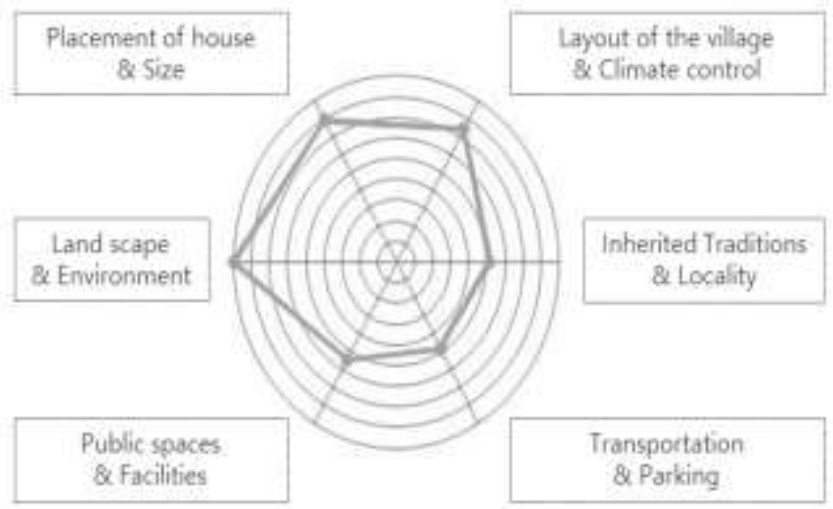

Figure 8. Degree of importance from New-Hanok Village

Two elements have a similar low point is Public spaces \& Facilities and Traditions \& Locality ranged between 6-6.5 points. Due to rising land prices should be reserved for public areas and parking, along with the inherited local traditions is significantly reduced space, more appropriate for contemporary occupy.

In this case, charting reflects the disparities between the elements a more detailed way of New-Hanok. Observing group is led by Natural scenery with 15.8 points, followed by the floor plan elements, utilizing natural terrain, climate control (9.2), pedestrian and bicycle road plans (7.2), and artificial Landscapes (7.1). Again, indicating the priority of environmental factors is indexed by climate, landscape around the residence and the transport sector to minor in order.

Group elements Space little note form (6.1), then the point descending from Formative value of Hanok (5.0), Community space, Road planning and parking plan, Characteristics of the region, The value of traditional materials, Eco space (3.0). These indicators reflect the declining importance of space for the community because contemporary life is increasingly hectic; the parking for large size vehicles have also been limited in confrontation with traditional and neither ecological time is minimized.

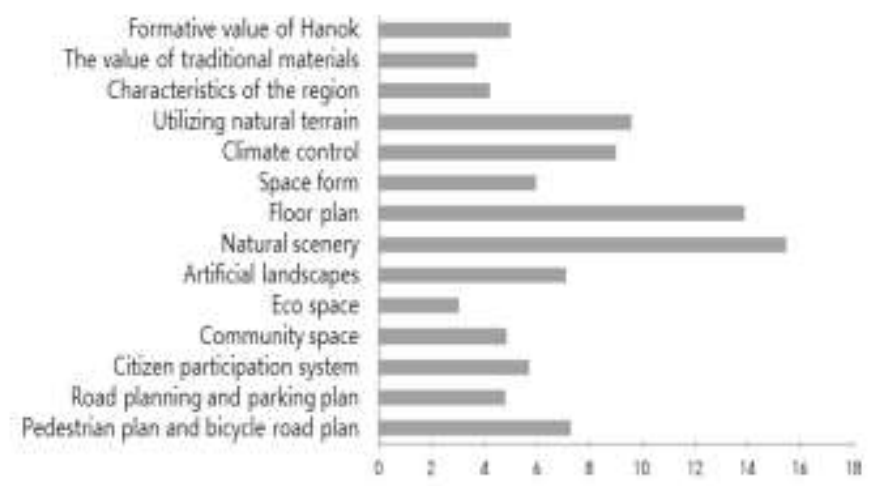

Figure 9. Degree of Importance from New-Hanok Village Analyses

\section{2) Selected Evaluation Destination}

In this section, we analyze and antagonize between Traditional and New Hanok Hanok through residential premises and the surrounding landscape with views overlooking from on high. Effortless to be recognized that by traditional layout with no certain order, quite spontaneously and keep the natural landscape around leads to the location of residence outside scenery angle to create the road small to according various curves.

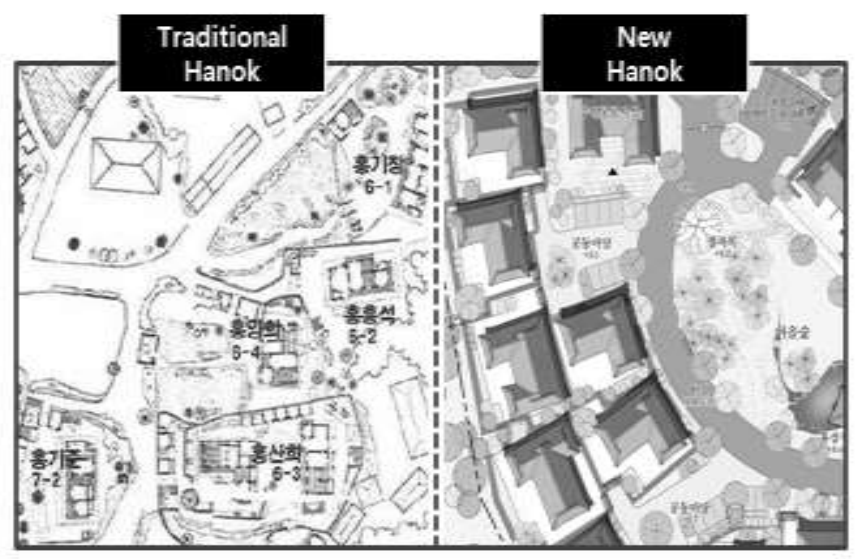

Figure 10. Select evaluation destination

In the premises of New Hanok have a position contrary to planning the buildings in a certain order, the surroundings are 
Proc. of The Third Intl. Conf. On Advances in Applied Science and Environmental Technology - ASET 2015

Copyright ( Institute of Research Engineers and Doctors, USA .All rights reserved.

ISBN: 978-1-63248-084-2 doi: 10.15224/ 978-1-63248-084-2-50

rearranged and retain some natural scenery fit and the way of the exclusive major construction and buildings is concentrated around the main aisle.

\section{3) Informal Assessment and Decision Indexes}

Comparative overviews for two charts showing the degree of importance from elements of New-Hanok and that of traditional Hanok elements of the expert surveys, easily recognized focus on inherited Hanok traditions \& locality and layout of the village \& climate control. Meanwhile two elements inherited landscape \& traditions \& locality environment and were more concerned with New-Hanok, elements Layout of the village \& climate control less are most concerned about.

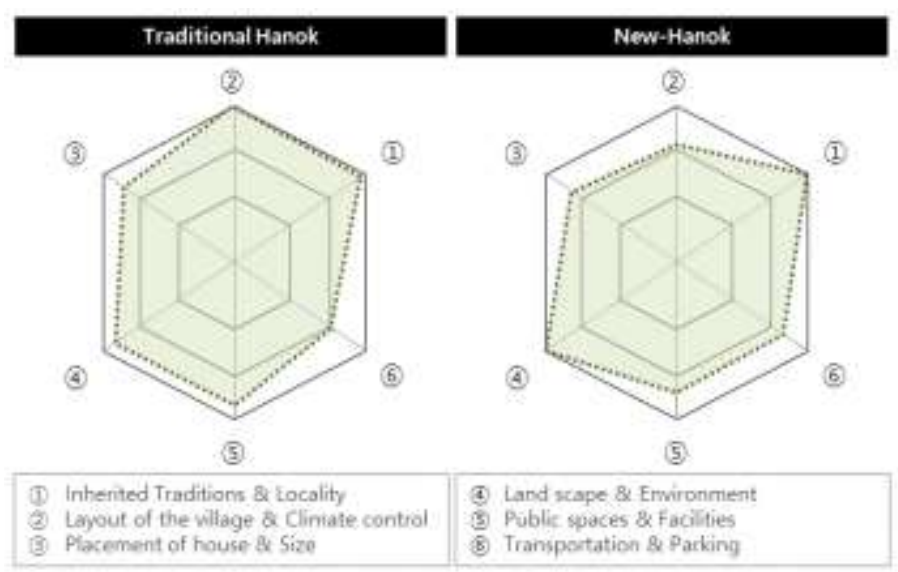

Figure 11. Decision ranking for traditional Hanok and New-Hanok

\section{v. Conclusion}

For this study, seven steps were performed to suggest evaluation process for Hanok Village. The first step was analyzed previous studies. Examining previous studies about the existing Hanok Village and its subsystem could be derived. The second step was to make a classification system. The classification system based on analysis of design standards for Hanok Village was suggested.

The third and fourth steps were to review the importance of the element derived from the survey expert. The fifth and sixth steps tried to improve VE evaluation system used by the informal VE team. They evaluated the traditional Hanok village and New-Hanok village. The final step used scores and weighting factors by evaluating the two villages was finally devised a score of villages.

Through this process to determine the Hanok's plan, residential properties, etc. and will be able to improve that lead to improvements in productivity, like I mentioned earlier.

On the other hand, this study is considered as a small experimental model of the survey personnel, a case constituting the Informal VE team and a greater number of experts are expected to be able to obtain a more accurate value if participation.

\section{Acknowledgment}

This research was supported by a grant (14AUDPB070933-02) from Urban Architecture Research Program (Development of Hanok Technology, Phase II) funded by Ministry of Land and Transport Affairs of Korean Government.

\section{References}

[1] H. Kim, February, 2013, A study on Design Supports to Improve Hanok Productivity, pp 17-18

[2] https://en.wikipedia.org/wiki/Productivity

[3] U.S. Dept. of Labor Bureau of Labor Statistics. "Multifactor Productivity-Frequently Asked Questions". Bureau of Labor Statistics. Retrieved 26 June 2014.

[4] H. Kim, February, 2013, A study on Design Supports to Improve Hanok Productivity, pp 27.

[5] Kwon, Y., Um, W. and Kim, H., March, 2011, A Design Guidelines for 'New-Hanok Maeul(Korean Traditional Style Village)', Proceedings of Architectural Institute of Korea, vol.27(3), pp.39-41, pp.45-50

[6] Prof Seung-Hoon Han \& Park, Decision-Marker with Value engineering process for designing New-Hanok Village in Korea, pp 3.

[7] H. Kim, February, 2013, A study on Design Supports to Improve Hanok Productivity, pp 17-18

[8] H. Kim, February, 2013, A study on Design Supports to Improve Hanok Productivity, pp 27.

[9] S. Kim, K. Kim, J. Park and S. Han, November, 2014, A Process of Value Assessment for Building Components of Hanok Residence, Proceeings of the Second International Conference on Advances in Computing, Communication and Information Technology (CCIT 2014).

[10] Kwon, Y., Um, W. and Kim, H., March, 2011, A Design Guidelines for 'New-Hanok Maeul(Korean Traditional Style Village)', Proceedings of Architectural Institute of Korea, vol.27(3), pp.39-41, pp.45-50

About Author (s):

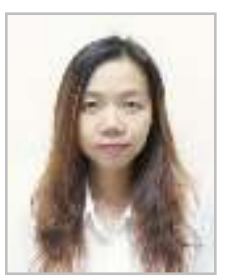

Pham Ngoc Quynh Giao

- Dotorate's Program, School of Architecture, Chonnam National University, Korea.

- Research Interests: Interior Design,

Architectural Planning, Creativity

Methodology of Architecture Design

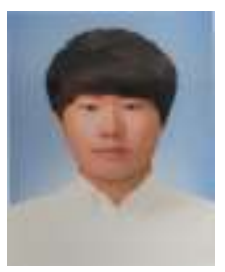

Jong-Il Park

- Master's Program, School of Architecture, Chonnam National University, Korea.

- Research Interests: Architectural Planning, Integrative Design, Spatial Behaviors and Performance Engineering

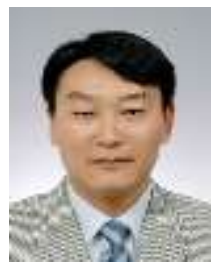

Seung-Hoon Han (Corresponding Author)

- Professor, School of Architecture,

Chonnam National University in Korea.

- Research Interests: Architectural Design,

Urban Planning, Building Information

Modeling and Performance Engineering 